\title{
The Effect Of Self-Efficiacy, Management Ability, Internal Communication And Job Satisfaction On Commitmentnormative Lecturers At Quality University Medan
}

\begin{abstract}
The problem in this study is whether there is an effect of self-efficacy, management ability, internal communication and job satisfaction on the normative commitment of lecturers at Quality University Medan. The population of this study amounts to 152 people and the sample amounts to 111 people. The results show that: Self-efficacy (X1) has a positive direct effect on lecturers' job satisfaction (X4) indicated that $\mathrm{p}_{41}=0,315$; Management Ability (X2) has a positive direct effect on job satisfaction (X4) indicated that $\rho_{42}=0,286$; Internal communication (X3) has a positive direct effect on job satisfaction (X4) indicated $\mathrm{f}_{43}=0,403$; Selfefficacy (X1) has a positive direct effect on organizational commitment (X5) indicated $\mathrm{p}_{51}=0,229$; Management Capability (X2) has a positive direct effect on organizational commitment (X5) indicated that $\rho_{52}=$ 0,188; Internal communication (X3) has a direct and positive effect on organizational commitment (X5) indicated that $p_{53}=0,276$; job satisfaction $(\mathrm{X} 4)$ has a positive direct positive effect on organizational commitment (X5) indicated that $\mathrm{p}_{54}=0,325$.
\end{abstract}

Keywords: Self Efficacy, Management Ability, Internal Communication

DOI: $10.7176 / \mathrm{JEP} / 10-6-16$

\section{INTRODUCTION}

Organizational commitment is one of the important points of attention that is based on the premise that individuals form a relationship with the organization. Some reasons why organizational commitment attracts attention are examined, among others, because committed lecturers will produce better performance than those who are less committed; because organizational commitment can be seen from the individual characteristics of the lecturer or workforce in improving the quality of teaching.

Quality University is as an institution of Higher Education that educate undergraduate with various professions to improve quality human resources. In order that the Quality University still exists, it must make changes to answer these demands. Bachelor of Quality University graduates have optimal quality, so they are able to compete in the world of labor at national, regional and international levels.

Research on organizational commitment needs to be done to lecturers because the commitment of lecturers to the university can influence the behavior of lecturers in the teaching-learning process, in interacting with students, coworkers and faculty or university leaders; and influence lecturer productivity in conducting research, writing scientific articles, and providing services to the community. Setiadi (2002) explains that the nature of organizational commitment is how the attitude and behavior of an employee towards the tasks charged by the institution where he works.

Based on the results of preliminary observations, there is still an indication of the ineffectiveness of work at the higher education institutions at Quality University Medan such as: the number of lecturers for a number of work units is very small and this is not in accordance with the volume of activities in the work unit. The work of the lecturer who overloaded and cause the expected target not to be achieved, the work that is too stressed on the final results so that group dynamics through communication and coordination are very few that caused low interpersonal relations, physical loyalty reflected in how long someone is inside the organization lecturers, there is a conflict between lecturers in the organization because each lacks a sense of obligation, causing ineffective resources available. This means that lecturers lack high normative commitment because they feel that they are not obliged to resistance in the organization, with less sense of moral responsibility. The normative commitment of the lecturer in the organization needs to be analyzed by determining the factors so that the normative commitment of the lecturer is more optimal. 
Based on the results of the analysis of the research conducted by Colquitt, Lepine, and Wesson, it is found that empirically there are several variables that influence organizational commitment. This shows that various variables found in influencing organizational commitment according to Colquitt, Lepine, and Wesson (2009: 8) are organizational cultures, organizational structure, leadership style and behavior, leadership power and influence, team, process, team, characteristics, cultural values and personality, and ability. In addition to Colquitt, Lepine, and Wesson the organizational behavior system of Newstrom, states variables (1) leadership, (2) communication, and (3) group dynamics, can affect variables (1) performance, (2) job satisfaction, and (3) personal growth and development.

Based on the description above, this study is conducted on the effect of self-efficacy, management ability, internal communication and job satisfaction on the normative commitment of lecturers at Quality University Medan. For this reason, it is necessary to identify the factors that influence the normative commitment of Quality University Medan lecturers, both directly and indirectly in order to find a model that effectively increases the normative commitment of lecturers at Quality Medan University.

\section{LITERATURE REVIEW}

\subsection{Normative Commitment}

Normative commitment is a person's obligation to stay within an organization for moral or ethical reasons. This commitment causes an employee to stay on a job because they feel obliged to do so. In other words, this normative commitment is related to the feeling of being obliged to continue working in an organization. Normative commitment is a feeling that requires staying in the organization due to the obligations and responsibilities of the organization based on consideration of employee norms, values and beliefs. Sense of the obligation shows human resources by continuing to work on the organization and also responsibility

Based on the description above, it can be concluded that conceptually normative commitment is the obligation to keep working and staying in the organization. This means that lecturers who have a normative commitment feel that they must stay in the organization. Operationally, the normative commitment of the lecturer is the obligation of the lecturer to continue working and staying in the organization, with indicators: having a sense of loyalty and responsibility

\subsection{Job satisfaction}

Job satisfaction is one of the important elements in an organization. This is due to job satisfaction can affect work behavior such as lazy, diligent, productive, etc., or has a relationship with several types of behavior that are very important in the organization. For more details, some definitions of satisfaction are raised.

Kreitner and Kinicki (2007: 271) define job satisfaction as an effectiveness or emotional response to various aspects of work. Handoko (2000) states job satisfaction is a pleasant or unpleasant emotional state with which employees view their employment. Meanwhile, Hariandja (2002) says that job satisfaction is the extent to which individuals feel positively or negatively various kinds of factors or dimensions or tasks in work. Mangkunegara (2001) describes that job satisfaction is a feeling that supports or does not support employees who are related to their work or their condition. According to Robbins (2003: 78) job satisfaction is a general attitude towards someone's work that shows the difference between the number of awards received by workers and the amount they believe they should receive.

Based on the description above, it can be synthesized conceptually that job satisfaction is a person's attitude towards work that reflects feelings towards his work. Operationally, it is synthesized that job satisfaction is the attitude or feeling of a lecturer in interpreting and carrying out his work professionally, with indicators: work itself, relationships fellow coworkers, opportunities for progress and development, freedom of work.

\subsection{Internal Communication}

Organizational communication is as a process of creating and exchanging messages in a network of interdependent relationships to overcome an uncertain or constantly changing environment. Onong (2009: 122) internal communication is the exchange of ideas between administrators and employees in an organization or agency that causes the realization of the organization complete with a distinctive structure and exchange of ideas horizontally and vertically in an organization that causes work to take place (management operations). 
Mangkunegara (2008: 145) defines that communication is the process of transferring information, understanding, and understanding of someone, a place, or something to something, place, someone else.

Based on the above understanding, it can be seen that internal communication is the delivery of information from someone to others. Communication will work well when mutual understanding arises. Good communication means the fabric of understanding between one party to the other, so that what is communicated can be understood, thought and implemented. The internal communication indicators in this study are: (1) Positive attitude, built up if people have a positive attitude towards themselves, positive feelings for communication situations in general are very important for effective interaction, (2) similarity, always respecting and respecting themselves and also other people by keeping the feelings of others, so that satisfying interactions are achieved, (3) openness, always open and honest in speaking, and behaving and having an open view in all situations and conditions, and (4) Empathy, it is attitude feel the feelings of others.

\subsection{Management Ability}

In a simple meaning, management is defined as cultivation, namely the process of organizing or managing an organization in achieving its desired goals. Many experts provide management understanding in order to obtain a clearer understanding.

Gaffar (1089) argues that management of education implies a systematic, systemic, and comprehensive cooperation process in order to realize national education goals. Management of education can also be interpreted as everything related to the management of the educational process to achieve its intended goals, both short-term, medium-term goals, and long-term goals which have been set. The process of controlling these activities includes planning, organizing, actualizing and controlling, as a process to make vision into action. Management of education is as an art and science of managing educational resources to create a learning atmosphere and learning process so that students actively develop their potential to have religious spiritual strength, self-control, personality, intelligence, noble character, and skills needed by themselves, national society and country.

Based on the above theoretical study, it can be synthesized conceptually that management capability is the ability in the process of implementing management functions to achieve goals effectively and efficiently. Operationally that management capability is the cognitive ability of the leader in the process of implementing management functions to achieve goals effectively and efficiently, with indicators of planning, organizing, directing, and controlling educational resources.

\subsection{Self-Efficacy}

The concept of self efficacy is actually the essence of social cognitive theory proposed by Albert Bandura who emphasizes the role of observational learning, social experience, and reciprocal determinism in the development of personality. Self-efficacy refers to the belief in the extent to which individuals estimate their ability to carry out tasks or perform tasks needed to achieve a certain outcome. Belief in all these abilities includes self-confidence, adaptability, cognitive capacity, intelligence and capacity to act in a stressful situation. Self-efficacy is the ability to realize, accept, and account for all potential skills or expertise appropriately.

Ormrod (2008: 20) depicts self-efficacy is a person's assessment of his own ability to carry out certain behaviors or achieve certain goals. It is a person's belief that he is able to do certain tasks well. It has effectiveness, that is, individuals are able to judge themselves as having the power to produce something they want. The perceived high self-efficacy motivates individuals cognitively to act appropriately and directed, especially if the goals to be achieved are clear goals. Individual thoughts on self-efficacy determine how much effort is devoted and how long individuals will survive in facing obstacles or experiences that are not pleasing. Alwisol (2009: 287) states that self-efficacy is a self-perception of how well self can function in certain situations, self-efficacy is related to the belief that self has the ability to do the expected actions.

Based on the explanation stated above, it can be conceptually synthesized that self-efficacy is the belief a person has about his ability to take the actions needed to reach the demands of the organization. Operationally that self-efficacy is the belief that the lecturer has about his ability to take the actions needed to achieve the demands of campus organizations, with indicators: confidence in involvement in tasks, confidence in his ability to face challenges, optimism, comfort while working and activities the hard one. 


\section{RESEARCH METHODS}

This research is conducted at the Quality University Medan. The selection of research sites within the Quality University Medan is because researchers want to conduct research on organizational commitment especially the normative commitment of lecturers at Quality University.

The population in this study is permanent lecturers at Quality University. In full, the population of the study can be seen in the Quality University lens taken based on the sampling area, which is 152 lecturers, while the sample of 111 respondents is then determined by the number of samples in each faculty spread across eight faculties.

\subsection{Data Analysis Technique}

Analysis of the data used in this study includes descriptive analysis, analysis requirements test, and hypothesis testing. In accordance with the research hypothesis and research objectives, testing hypotheses is done using Path Analysis.

\subsection{Test the Research Hypothesis}

To test the hypothesis, path analysis is used with the help of a computer program SPSS for Windows version 24.0. In testing hypotheses, a significance level of $\alpha$ of 0.05 is used. In connection with the use of path analysis, Al-Rasjid suggests that when conducting an analysis, it must be first to described in a diagrammatic structure of causal relationships with causal variables and consequent variables. Based on theoretical models developed in research this is as the model used the path diagram of the research variable.

$\mathrm{X} 1=$ Self Efficacy

X2 = Management Capability

$\mathrm{X} 3=$ Internal Communication

$\mathrm{X} 4=$ Job Satisfaction

X5 = Normative Commitment

\subsection{Discussion of Research Results}

The description of the data presented in this section includes the variable data of Self-Efficacy (X1), Management Ability (X2), Internal Communication (X3), Job Satisfaction (X4), and Normative Commitment of Lecturers (X5). The data are the result of quantifying respondents' answers to the questionnaire distributed to lecturers at Quality University Medan. The number of questionnaires distributed is 111 sets according to the number of research samples. The data description for each research variable is presented in summary in the following Table.

Table 1. Summary of Calculation of Descriptive Statistics for Research Data

\begin{tabular}{|c|c|c|c|c|c|c|}
\hline \multicolumn{7}{|c|}{ Statistics } \\
\hline & & $\mathrm{X} 1$ & $\mathrm{X} 2$ & $\mathrm{X} 3$ & $\mathrm{X} 4$ & $\mathrm{X} 5$ \\
\hline \multirow[t]{2}{*}{$\mathrm{N}$} & Valid & 111 & 111 & 111 & 111 & 111 \\
\hline & Missing & 0 & 0 & 0 & 0 & 0 \\
\hline \multicolumn{2}{|c|}{ Mean } & 111,27 & 26,44 & 106,43 & 113,74 & 123,29 \\
\hline \multicolumn{2}{|c|}{ Std. Error of Mean } & 1,297 & ,491 & 1,244 & 1,310 & 1,473 \\
\hline \multicolumn{2}{|c|}{ Median } & 111,00 & 27,00 & 106,00 & 113,00 & 122,00 \\
\hline \multicolumn{2}{|c|}{ Mode } & 102 & $26^{\mathrm{a}}$ & $100^{\mathrm{a}}$ & 101 & $113^{\mathrm{a}}$ \\
\hline \multicolumn{2}{|c|}{ Std. Deviation } & 13,660 & 5,175 & 13,106 & 13,801 & 15,514 \\
\hline \multicolumn{2}{|c|}{ Variance } & 186,599 & 26,776 & 171,757 & 190,467 & 240,680 \\
\hline \multicolumn{2}{|c|}{ Range } & 52 & 21 & 53 & 51 & 57 \\
\hline \multicolumn{2}{|c|}{ Minimum } & 85 & 14 & 80 & 87 & 95 \\
\hline \multicolumn{2}{|c|}{ Maximum } & 137 & 35 & 133 & 138 & 152 \\
\hline \multicolumn{2}{|c|}{ Sum } & 12351 & 2935 & 11814 & 12625 & 13685 \\
\hline
\end{tabular}

Next, the statistical computation of the correlation coefficients and the path coefficients and their tests are summarized in Table 2 below. 
Table 2. Summary of Results of Correlation Coefficient Calculations, Path Coefficients and Meanings

\begin{tabular}{|c|l|l|l|l|l|}
\hline Number & $\begin{array}{c}\text { Coefficient } \\
\text { Correlation* }\end{array}$ & $\begin{array}{c}\text { Path } \\
\text { Coefficient }\end{array}$ & $\mathrm{T}_{\text {count }}$ & $\mathrm{t}_{\text {table }}$ & Information \\
\hline 1 & $r_{14}=0,660$ & $\mathrm{p}_{41}=0,315$ & 4,612 & 1,98 & Path Means \\
\hline 2 & $r_{24}=0,625$ & $\mathrm{p}_{42}=0,286$ & 4,324 & 1,98 & Path Means \\
\hline 3 & $r_{34}=0,700$ & $\mathrm{p}_{43}=0,403$ & 5,917 & 1,98 & Path Means \\
\hline 4 & $r_{15}=0,676$ & $\mathrm{p}_{51}=0,229$ & 3,349 & 1,98 & Path Means \\
\hline 5 & $r_{2 \mathrm{E}}=0,630$ & $\mathrm{p}_{52}=0,188$ & 2,873 & 1,98 & Path Means \\
\hline 6 & $r_{3 \mathrm{E}}=0,710$ & $\mathrm{p}_{53}=0,276$ & 3,856 & 1,98 & Path Means \\
\hline 7 & $r_{45}=0,787$ & $\mathrm{p}_{54}=0,325$ & 3,674 & 1,98 & Path Means \\
\hline
\end{tabular}

Furthermore, based on the prices of the correlation coefficients and path coefficients obtained from the results of calculations, it can be described Path Diagram which is the relationship between the variables above, illustrated through a constellation model such as Figure 1.

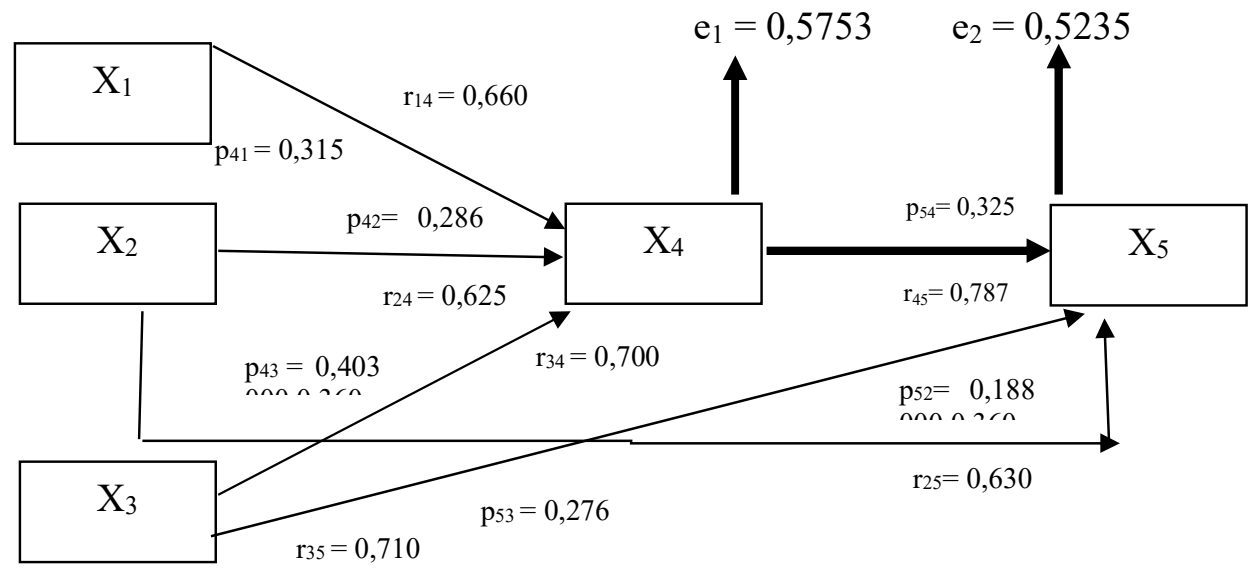

Figure 1. Theoretical Model of Kesearch

$\mathrm{X} 1=$ Self-efficacy

$\mathrm{X} 2$ = Management Capability

$\mathrm{X} 3$ = Internal communication

$\mathrm{X} 4=$ Job Satisfaction

$\mathrm{X} 5$ = Normative Commitment

e1, e2 = residual variable (error)

\subsection{Direct and Indirect Effects}

Based on the calculation results, a summary of the relative effect of self-efficacy (X1), Management Capability (X2), Internal Communication (X3), and Job Satisfaction (X4) is directly and positively affected by Normative Commitment (X5) as in Table 4.23 below. 
Table 4.23 The Coefficient Value of the Direct, Indirect, Total, and Non-Path Effect

\begin{tabular}{|c|c|c|c|c|c|c|c|}
\hline \multirow[t]{2}{*}{ Model } & \multirow{2}{*}{$\begin{array}{c}\text { Exogenous } \\
\text { Variable on } \\
\text { Endogenous } \\
\text { Variable }\end{array}$} & \multicolumn{3}{|c|}{ Causal Effect } & \multicolumn{2}{|c|}{ Non Path } & \multirow{2}{*}{$\begin{array}{c}\text { Correlati } \\
\text { on }\end{array}$} \\
\hline & & Direct & $\begin{array}{l}\text { Indirect } \\
\text { trough } X_{4}\end{array}$ & $\begin{array}{l}\text { Total } \\
\text { effect }\end{array}$ & $\mathrm{U}$ & $\mathrm{S}$ & \\
\hline \multirow[b]{3}{*}{$1^{\mathrm{a}}$} & $\mathrm{X}_{1}$ toward $\mathrm{X}_{4}$ & 0,315 & - & 0,315 & 0,344 & & 0,660 \\
\hline & $\mathrm{X}_{2}$ toward $\mathrm{X}_{4}$ & 0,286 & - & 0,286 & 0,338 & & 0,625 \\
\hline & $\mathrm{X}_{3}$ toward $\mathrm{X}_{4}$ & 0,403 & - & 0,403 & 0,296 & & 0,700 \\
\hline \multirow[b]{4}{*}{$2^{\mathrm{b}}$} & $\mathrm{X}_{1}$ toward $\mathrm{X}_{5}$ & 0,229 & 0,215 & 0,444 & 0,232 & & 0,676 \\
\hline & $\mathrm{X}_{2}$ toward $\mathrm{X}_{5}$ & 0,188 & 0,203 & 0,391 & 0,238 & & 0,630 \\
\hline & $\mathrm{X}_{3}$ toward $\mathrm{X}_{5}$ & 0,276 & 0,228 & 0,504 & 0,206 & & 0,710 \\
\hline & $\mathrm{X}_{4}$ toward $\mathrm{X}_{5}$ & 0,325 & - & 0,325 & & $\begin{array}{c}0,46 \\
2\end{array}$ & 0,787 \\
\hline
\end{tabular}

Description: $\mathrm{U}=$ Unanalyzed Component, and $\mathrm{S}=$ Spurious Component

To determine the magnitude of the influence between self-efficacy (X1), Management Ability (X2), Internal Communication (X3), job satisfaction (X4) (model I), and the magnitude of influence between selfefficacy (X1), Management Capability (X2), Communication Internal (X3), and job satisfaction (X4) on Normative Commitment (X5) (model II) are obtained from a summary model, especially the R square number obtained from the output of the SPSS application program as follows.

Table 3. Model Summary

\begin{tabular}{|c|c|c|c|c|}
\hline Model & $\mathrm{R}$ & R Square & $\begin{array}{c}\text { Adjusted R } \\
\text { Square }\end{array}$ & $\begin{array}{c}\text { Std. Error of the } \\
\text { Estimate }\end{array}$ \\
\hline$I$ & $0.818^{\mathrm{a}}$ & 0.669 & 0.659 & 8.056 \\
\hline$I I$ & $0.852^{\mathrm{a}}$ & 0.726 & 0.715 & 8.279 \\
\hline
\end{tabular}

Based on the data obtained that $\mathrm{KD}=\mathrm{R} 2 \times 100 \%$, it can be calculated Model I determination coefficient of $67 \%$ which means that the effect of Self-Efficacy (X1), Management Capability (X2), Internal Communication (X3) is combined against job satisfaction (X4) is $67 \%$ while the remaining $33 \%$ is influenced by other factors. Furthermore, the coefficient of determination of Model II obtained from the calculation results is $73 \%$, which means that the effect of self-efficacy (X1), Management Ability (X2), Internal Communication (X3), and job satisfaction (X4) on Normative Commitment (X5) is $73 \%$, while the remaining $27 \%$ is influenced by other factors.

\section{RESULT AND DISCUSSION}

The results of this study partially show that the self-efficacy variable (X1) has a positive direct effect on Job Satisfaction (X4) of Lecturers at Quality University Medan with the acquisition that $\mathrm{p}_{41}=0,315 \mathrm{nd}$ significance $>0.05$; means that Ho is rejected or Ha is accepted thus it can be concluded that Self-efficacy (X1) has a positive direct effect on Job Satisfaction (X4) Lecturer at Quality University Medan. This implies an increase of 1 variable unit Self-efficacy will increase the variable work satisfaction of lecturers by 0.315 units assuming other variables are considered constant.

Data distribution Self-efficacy that 54,955 percent is included in the sufficient category, and 45,045 percent in the category is less. So overall, it can be concluded that the self-efficacy of Quality Medan University 
lecturers tends to be in the sufficient and less category. So overall it can be concluded that the self-efficacy of Quality Medan University lecturers tends to be in the sufficient and less category.

The findings of this study are in accordance with the results of the Situmorang study (2012: 166) which found that self-efficacy had a significant positive direct effect on Normative Commitment. Thus, the suitability of the findings of this study with the results of the Situmorang study and the theory used as the basis for the research hypothesis showed that the theory was still accurately used answer relevant problems. With a good culture, it will be able to improve the job satisfaction of lecturers at Quality University Medan. Among the cultures that are expected to be good cooperation among fellow lecturers which ultimately increases the job satisfaction of the lecturer itself. Job satisfaction is an emotional state where it does not occur a meeting point between the values of the worker's remuneration from the school with the desired level of remuneration. The job satisfaction of the Quality University Medan is the level of pleasure someone feels for his role or work in the organization. People who work expect to get the satisfaction from where they work. Basically, job satisfaction is an individual thing because each individual will have a different level of satisfaction in accordance with the values that occur in each individual. The more aspects of work that are in accordance with individual desires, the higher the level of satisfaction felt.

Based on the results of testing the eight hypotheses as described above found a fixed model or theoretical model that describes the causal relationship between research variables that determine vertical communication which is the development of several theories, mainly "Integrative Model of Organizational Behavior" from Colquitt, LePine, and Wesson ; Situmorang's theoretical relationship model is the effect of selfefficacy, leadership, interpersonal communication, and performance on Normative Commitments; and the Siburian theoretical relationship model namely interpersonal communication, self-efficacy, performance and achievement motivation towards organizational structure.

The results of this study are also in accordance with the research of Quresi et al. (2011) according to finding that increasing factors and reducing job satisfaction will influence Normative Commitments. This shows that lecturers at Quality Medan University do not have good job satisfaction. So, the lecturer at Quality University Medan has not been able to complete difficult tasks, working without prioritizing their own abilities and business.

Based on the results of hypothesis testing which accepts the eight research hypotheses proposed as described above, it is found a Theoretical Model Normative Commitment lecturer which is a development of several theories, mainly "Integrative Model of Organizational Behavior" from Colquitt, LePine, and Wesson; "An Organizational Behavioral System ". Normative Commitment Model findings of this study explain that increasing Normative Commitment can be built through the strengthening of Self-Authentication, Management Capability, Internal Communication and Job Satisfaction which can be adaptively implemented at Quality Medan University. Strengthening Self-Efficacy, Management Capability, Internal Communication causes higher job satisfaction, which in turn will make the commitment better.

\section{CONCLUSION}

Based on the previous descriptions and the results of data analysis and discussion of the results of the research conducted, the Normative Commitment Adaptive Dosage model implemented at the Quality University Medan is built on associative causal relationships between exogenous variables Self Efficacy, Management Capability, Internal Communication, and Job Satisfaction with endogenous variables Commitment Normative Lecturer. The Lecturer Normative Commitment Model from the findings of this study explain that increasing Normative Commitment of Lecturers can be done in two ways, namely: strengthening self-efficacy, management ability, internal communication, and job satisfaction Knowledge Management Education, Work Motivation, and Job Satisfaction that directly cause The Normative Commitment gets better. In addition, it can also be done through strengthening self-efficacy, management ability, internal communication which will directly result in increased job satisfaction which further increases the normative commitment of lecturers to be better.

\section{REFERENCES}

Alwisol. 2009. Personality Psychology: Revised Edition. Malang: UMM Press.

Benyamin Situmorang. 2012. The Effect of Organizational Culture, Leadership, Interpersonal Communication, and Job Satisfaction on the Principal's Organizational Commitment. Dissertation (Medan: Undergraduate Program, Medan State University) 
Colcuit, Jason A., Jeffery A., LePine., And Michael J. Wesson. 2009. Organizational Behavior: improving performance and commitment in the workplace. New York: McGraw-Hill.

Gaffar, M.F. 1989. The Educational Planning, Theory and Methodology. Jakarta: Ministry of Education and Culture, Director General of Higher Education-P2LPTK.

Gary Desler. 2010. Human Resource Management. Jakarta: PT. Index.

Gibson, J.L; Ivancevich, J.M; Donnelly, Jr. J.H; and Konopaske, R. 2009., Organizations: Behavior, structure, processes, 13th. Irwin, New York: McGraw-Hill, 2009.

Handoko, T. Hani. 2000. Management. Issue 2. Yogyakarta: BPFE.

Hariandja, Marihot T.E. 2002. Human Resource Management. Jakarta: Grasindo.

Kreitner, Robert and Kinicki. 2007. Organizational Behavior. 8th Edition. Boston: McGraw-Hill.

Mangkunegara. A. P. 2001. Human resource management company, Bandung: Teenager Rosdakarya.

Mangkunegara. A..2008, Human Resource Management. Bandung: Teenager Rosdakarya, 2008.

Onong Uchjana. 2009. Communication Theory and Practice. Contents: PT Adolescent Rosdakarya, 2009.

Ormrod, Jeanne. Ellis. 2008. Educational Psychology Developing Learners Sixth Edition (Educational Psychology Volume 2) 6. Interpreting: Amitya Kumara. Jakarta: Erlangga.

Qureshi, Khansan Hayat, Mehwish Ali, \& Nosheen Sarwat. 2011. Impact of Job Satisfaction and Organizational Commitment on Employee Performance, Evidence from Pakistan. Institute of Interdisciplinary Business Research. (Vol.3No.4, pp.642-657, 2011)

Robbins, P. Stephen and Timothy A. Judge. 2009. Organizational Behavior. Salemba Empat. Jakarta. Robbins, Stephen P. 2003. Organizational Behavior. Index. Jakarta.

Setiadi J Nugroho. 2002. Consumer Behavior: Concepts and Implications for Business Marketing Strategy and Research. Prenada Media, Jakarta. 